\title{
Simple measuring method for electro-optic coefficients in poled polymer waveguides
}

\author{
Winfried H. G. Horsthuis \\ Akzo Research Laboratories Amhem, Corporate Research, Applicd Physics Department, P. O. Box 9300, \\ 6800 SF Amhem, The Netherlands \\ Giis J. Krijnen \\ Twente Unwersity. Faculty of Elecrrical Engineering, P. O. Box 217, 7500 AE Enschede, The Netherlands
}

(Received 22 March 1989; accepted for publication 31 May 1989)

\begin{abstract}
A simple measuring technique for the linear electro-optic coefficients in electro-optic waveguides is described. The method is based on the direct evaluation of synchronous angle measurements obtained by prism coupling. No waveguide or electrode patterning is required. A model has been developed in order to simulate the relation between change in synchronous angle and applied electric field across the electro-optic waveguide. The measured values of the electro-optic coefficients in poled polymer waveguides are reported.
\end{abstract}

Recently, progress has been reported in the development of noninear optical polymers for use in integrated optic devices. ${ }^{1-5}$ These materials offer advantages as compared to inorganic materials (e.g., Lipo $\mathrm{F}_{3}$ ). Polymers can be deposited on a variety of substrates, such as glass, metal semiconductors, plastic, or ceramic, on which electronic circuitry may already be present. Large electro-optic coefficients for nonlinear polymers have been reported. ${ }^{4}$ Moreover; polymer-based devices can be designed in such way that optical and switching (electrical) fields overiap optimally, resulting in high cfficiencies.

Apart from molecular measurements such as electric field induced scond-harmonic generation in solutions, ${ }^{6}$ waveguiding properties have been determined by studying prototype integrated optic devices." In this letter we report on the measured electro-optic Pockels coefficients of poled polymer waveguides obtained by a simple measuring scheme based on the direct use of the prism-coupling technique. This technique reveals the optical properties of polymers in true waveguiding configuration without the need of manufacturing a complete device. Test samples consisted, from botrom to top, of a silicon substrate ( $p$ type, $5 \Omega \mathrm{cm}$ ), a spin-coated polymer buffer layer ( $\approx 1.1$ pm thickness), a core of a nonlinear polymer, and a very thin top electrode.

A cross-sectional view of a test sample is given in Fig. 1 . The nonlinear polymer is an amorphous sice-chain polymer incorporating methoxynitrostibene groups developed by Akzo Corporate Research Labs. Since in such systems the electro-optic groups are initially oriented at random, electric field poling is a necessary step to obtain an electro-optically active thin fllm. Some basic data of the polymer are listed in Table 1 .

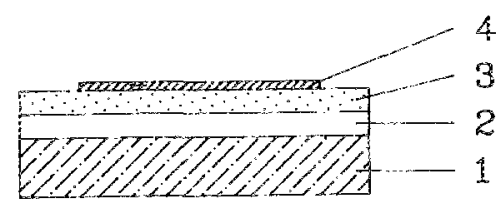

FIG. 1. Cross section of a typical test sample. (1) silicon substrate $(\rho=5$ $\Omega \mathrm{cm}$ ), (2) polymer buffer, $n=1.55, d-1.5 \mu \mathrm{m},(3)$ nonlinear polymer corc, $d=1.5 \mu \mathrm{m}$, (4) silver top electrode, $d=25 \mathrm{~nm}$.
After the deposition of the top electrode the sample was poled as follows. First, it was heated to the glass transition temperature $\left(T_{g}\right)$ on a hot plate. Then a voltage was applied to the two electrodes giving rise to an electric field across the active core. The reorientation process of the molecular groups takes only a few seconds. With remaining electric field, the heater was switched off, and the sample was cooled with an air blower. Finally, the field was switched off at a temperature well below $T_{g}$. Total time of the poling action was about 4 min, including up and down ramping. Figure 2 gives a graphic representation of the poling sequence.

Prism coupling was used to determine film thickness and refractive indices of the core both before and after the poling process. In order to measure these properties of the poled sample, the top electrode was locally removed. Since poling leads to a partial orientation of the active groups, the polymer core becomes birefringent. This poling-induced birefringence is a direct measure of the poling efficiency, Calculations indicate that the change in refractive index parallel to the poling field will be twice as large and of opposite sign compared with the change in index perpendicular to the poling field. The experimenta results given in Table $I I$ are in reasonable agreement with these expectations.

To determine the Pockels coefficient, we used the prismcoupling technique as well. It appeared feasible to launch some waveguide modes even with the prism placed on top of the electrode, provided this electrode is very thin and does not abserb too strongly. 25-nm-thick silver layers turned out to meet these requirements.

Since the propagation constants of the modes of the structure strongly depend on the refractive index of the core,

TALEE I. Properties of Akzo nonlinear polymer ADK77.

\begin{tabular}{ll}
\hline Active group & methoxy-nitro-stibene (MONS) \\
Hyperpolarizability MONS & $250 \times 1040 \mathrm{~m}^{4} / \mathrm{V}^{\mathrm{a}}$ \\
Group density (wt. \%) & $45 \%$ \\
Abscrotion max. & $360 \mathrm{~nm}$ \\
Glass transition point & $405 \mathrm{~K}$ \\
Refractive index & $1.617($ at $633 \mathrm{~nm})$ \\
Waveguide atteruation & $3 \mathrm{~dB} / \mathrm{cm}(\mathrm{at} 633 \mathrm{~nm})$ \\
& $<1 \mathrm{~dB} / \mathrm{cm}(\mathrm{at} 821 \mathrm{~nm})$ \\
\hline
\end{tabular}

"Reference 6. 


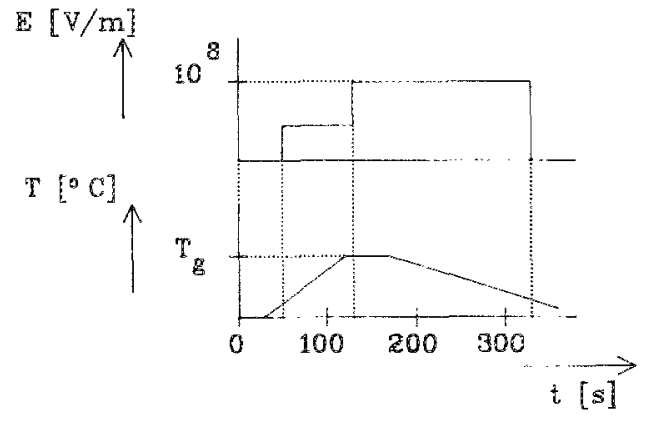

FIG. 2. Typical poling sequence of an electro-optic polymer.

the synchronous angle will be changed when an electric field is applied across the electro-optic waveguide. By this method, different poling conditions can be evaluated using the same sample.

The relation between a change in the applied electric field $\Delta E$ and the resulting change in synchronous angle $\Delta \alpha$ can be written as

$$
\Delta \alpha=\frac{d \alpha}{d n_{2}} \Delta n_{2}=\frac{d \alpha}{d n_{\mathrm{eir}}} \frac{d n_{\mathrm{etr}}}{d n_{2}} \Delta n_{2}
$$

where $n_{\text {eff }}$ is the mode effective refractive index and $n_{2}$ is the core refractive index. The field-induced change in $n_{2}$ is given by

$$
\Delta n_{2}=-\frac{1}{2}\left(n_{2}\right)^{3} r_{i 3} E
$$

with $i=1$ or 3 for transverse electric ( $T E$ ) and transverse magnetic (TM) modes, respectively.

We have implemented a simulation program capable of calculating the guided modes of slab waveguides with complex dielectric constants. The calculations are based on a direct formulation of the Maxwell equations for the continuity of the fields and the derivatives of the fields at the interfaces of a multilayer structure. 'By means of this program we determined the variation in synchronous angles with $\Delta n_{2}$ for the fundamental transverse magnetic (TM) mode of the structure depicted in Fig. 1. Using these results, the relation between the electro-optic $r_{33}$ coefficient and synchronous angle variation can be obtained by substitution of $\mathrm{Eq}$. (2) in Eq. (1). Figure 3 shows the calculated resuls. An the materials, inchuding silicon substrate and prism, have been incorporated in the calculations. The width of the air gap between a silver layer and prism is estimated to be $50 \mathrm{~nm}$. Calculations showed that the slope of the curves in Fig. 3 is hardly dependent on this air-gap width.

TABLE 11. Measured refractive indices before and after poling, at $633 \mathrm{~mm}$ (HeNe laser), with $n_{e}$ the extraordinary index (paralle! with poling field)

\begin{tabular}{|c|c|c|c|c|c|}
\hline \multirow{2}{*}{$\begin{array}{c}\text { Sample } \\
\text { No. }\end{array}$} & \multicolumn{2}{|c|}{$\begin{array}{l}\text { Refractive } \\
\text { indices } \\
\text { before poling }\end{array}$} & \multicolumn{2}{|c|}{$\begin{array}{l}\text { Refractive } \\
\text { indices } \\
\text { after poling }\end{array}$} & \multirow{2}{*}{$\begin{array}{c}\text { Poling } \\
\text { field } \\
\left(10^{7} \mathrm{~V} / \mathrm{m}\right)\end{array}$} \\
\hline & $n_{e}$ & $n_{0}$ & $n_{i}$ & $n_{u}$ & \\
\hline 1 & 1.617 & 1.619 & 1.640 & 1.612 & 11 \\
\hline 2 & 1.617 & 1.619 & 1.655 & 1.605 & 13 \\
\hline 3 & 1.617 & 1.619 & 1.638 & 1.608 & 11 \\
\hline 4 & 1.517 & 1.619 & 1.625 & 1.615 & 8 \\
\hline
\end{tabular}
and $n_{0}$ on the ordinary index (perpendicular to poling field).

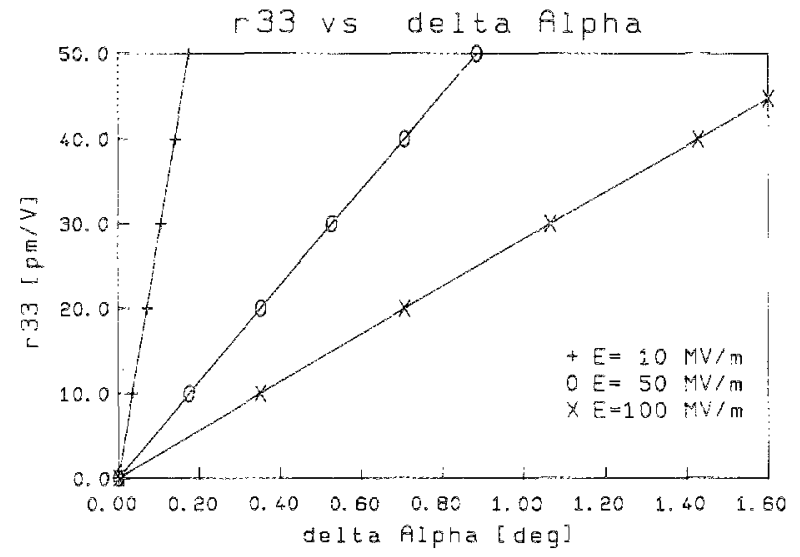

FIG. 3. Calculated relation between measured change in coupling angle and electro-optic cuefficient $r_{33}$ for three different applied electric fields. Calculations apply for the $\mathrm{TM}_{0}$ mode in a waveguide as shown in Fig. 1.

Finally, the $r_{33}$ and, if possible, the $r_{13}$ coeficients were measured on the same samples using synchronous angle measurements with the prism placed near the edge and upon the top electrode. The input light beam was mechanically chopped. With no voltage applied to the electrodes, the synchronous angle was determined by monitoring the scattered intensity of the guided wave with an optical fiber and photodode arrangement connected to a lock-in amplifier. Then at voltage was applied, resulting in a decreased coupling efirciency. The coupling angle for maximum coupling efficiency was measured again and used for the calculation of $n_{2}$ from which $\Delta n_{2}$ and $r_{33}$ were determined. Since we employed the same electrode configuration for poling and Pockels coefficient measurements, the $r_{33}$ is obtained using TM modes, whereas the $r_{13}$ coefficient is evaluated from the TE mode measurements. However, only TM modes were easy to be launched through the silver layer. For only one sample the $\mathrm{TE}_{0}$ mode was also clearly visible, permitting the calculation of the $r_{13}$ coefficient for that specific sampie. Tabie III summarizes the measured results.

In conclusion, we developed a measuring scheme by which the linear electro-optic evaluation of newly developed nonlinear optical materials can easily be performed. Meásurements of poled polymers revealed high nonlinear coeffi-

TABLE YII. Measured Pockels coefficients in poled polymer films (with

\begin{tabular}{|c|c|c|c|c|c|c|}
\hline Sample & Poling fiefd & Applied field & $\begin{array}{c}\Delta \alpha \\
(\mathrm{deg})\end{array}$ & & $\begin{array}{c}r_{3,3} \\
(\mathrm{pm} / \mathrm{V})\end{array}$ & $\begin{array}{c}r_{i 3} \\
(\mathrm{pm} / \mathrm{V})\end{array}$ \\
\hline No. & $\left(10^{7} \mathrm{~V} / \mathrm{m}\right)$ & $\left(10^{7} \mathrm{~V} / \mathrm{M}\right)$ & +0.02 & Mode & \pm 2 & \pm 2 \\
\hline$i$ & 11 & --3 & -0.13 & $T M_{0}$ & 11 & $\cdots$ \\
\hline 1 & 11 & 3 & 0.15 & $\mathrm{TM}_{0}$ & 13 & $\cdots$ \\
\hline 1 & $\llbracket$ & 5 & 0.23 & $T M_{i j}$ & 12 & $\cdots$ \\
\hline 2 & -13 & -3 & 0.24 & $\mathrm{TM}_{4}$ & -20 & $\cdots$ \\
\hline 2 & -13 & 3 & -0.23 & $\mathrm{TM}_{\mathrm{i}}$ & -19 & $\cdots$ \\
\hline 2 & -13 & 5 & -0.36 & $\operatorname{TM}_{3}$ & -18 & $\cdots$ \\
\hline 3 & 9 & 2.6 & 0.12 & $T M_{1}$ & 15 & $\cdots$ \\
\hline 3 & 9 & 2.6 & 0.09 & $\mathrm{TM}_{2}$ & 17 & $\cdots$ \\
\hline 3 & 9 & 2.6 & 0.04 & $T M_{1}$ & $\cdots$ & 6 \\
\hline 3 & 9 & 4.5 & 0.17 & $\mathrm{TM}_{3}$ & 13 & $\cdots$ \\
\hline 3 & 9 & 4.5 & 0.13 & $T M_{2}$ & 14 & .. \\
\hline 3 & 9 & 4.5 & 0.08 & $T E_{1}$ & $\cdots$ & 6 \\
\hline
\end{tabular}
$\Delta \alpha$ the change in coupling angle). 
cients of the order of $18 \mathrm{pm} / \mathrm{V}$, using active groups with only a moderate molecular hyperpolarizability.

'K. D. Singer, M. G. Kuzyk, W. R. Holland, J. E. Sohn, and S. J. Lalama, Appl. Phys. Letr. 33, 1800 (1988).

'S. Esselin, P. le Barny, P. Robin, D. Broussoux, J. C. Dubois, J. Raffy, and 3 . P. Pocholle, Proceedings of the SPIE Symposium on Optical and Optoelectronic Applied Science and Engineering, San Diego, 1988 (SPIE, Washingion, D.C., 1988), Vol. 971, p. 120.
32. Pantelis, J. R. Hill, S. N. Oliver, and G. J. Davies, Er. Telecom, Technoi. J. 6.5 (1988)

${ }^{4}$ G. R. Moehlmann, W. H. G. Forsthuis, M. R. J. Diemeer, F. M. M. Suyten, E. S. Trommel, A. McDonach, and N. McFadyen, Nonlinear GuidedWave Phenomena: Physies and Applications, Optical Society of America, 1989 Technical Digest Series, 2, 171 (1989).

5. I. Thackara, G. F. Lipscomb, M. A. Stiller, A. I. Ticknor, and R. Lytel, Appl. Whys. Lett. 52, 1031 (1988).

${ }^{6}$ R. A. Fuijts and G. L. J. Hesselink, Chem. Phys. Lett. 156, 209 (1989). D. Narcuse, J. Lightwave Technol. HT-5, 113 (1987). 